\title{
The Effectiveness of Treatment Training for Children with Acute Respiratory Tract Infection to Mothers of Toddlers in Bandung Indonesian
}

\author{
Henny Cahyaningsih, Sri Kusmiati, Ahmad Husni \\ Nursing Department of Bandung Health Polytechnic, Ministry of Health, Bandung, Indonesia \\ Email: henny.lukman032@gmail.com
}

How to cite this paper: Cahyaningsih, H., Kusmiati, S. and Husni, A. (2017) The Effectiveness of Treatment Training for Children with Acute Respiratory Tract Infection to Mothers of Toddlers in Bandung Indonesian. Open Journal of Nursing, 7, 759-769. https://doi.org/10.4236/ojn.2017.77057

Received: March 27, 2017

Accepted: July 17, 2017

Published: July 19, 2017

Copyright $\odot 2017$ by authors and Scientific Research Publishing Inc. This work is licensed under the Creative Commons Attribution International License (CC BY 4.0).

http://creativecommons.org/licenses/by/4.0/ (c) (i) Open Access

\begin{abstract}
Acute Respiratory Tract Infection (ARTI) remains a health problem for toddlers in Indonesia and the leading cause of death for toddlers. In addition to causing health problems, ARTI can also cause death. Indonesia, as one of the countries signing of the Millennium Development Goals (MDGs), is required to be able to reduce toddler mortality rate. The research intends to find the effectiveness of treatment training for children with ARTI in increasing the knowledge, attitude, and skill of mothers of toddlers in the working area of Community Health Centre Sukajadi, Bandung. It employed a quasiexperimental method with the pre-posttest two group designs. The sample, taken with the random sampling technique, consisted of 26 mothers of toddlers for the control and intervention groups, respectively. For the intervention group, the treatment training for children with ARTI was given for 4 - 5 hours in one day, and the control group was only given a conventional extension program for 15 minutes. The knowledge, attitudes, and skills before and after intervention were measured three days after the training using the same instrument used during the pretest. The results of this research show that in terms of the effectiveness of the training using modules, there were differences in the average scores for knowledge with $p$ value $(0.030 \leq \alpha(0.05)$, for the aspect of attitudes with $p$ value $(0.046) \leq \alpha(0.05)$, and for the sub-variable of skills as proven by the $p$ value of $(0.046) \leq \alpha(0.05)$. Based on these results, the intervention of ARTI treatment training at home had significant effect on the knowledge, attitudes, and skills of the toddlers' mothers. With this inference, it is recommended that the research results can be made a topic of study for the development of a training model or standardized training guidelines that will be used by health officers at Community Health Centre Sukajadi, Bandung City Indonesian.
\end{abstract}




\section{Keywords}

Training, ARTI, Knowledge, Attitude, Skill

\section{Introduction}

Acute respiratory tract infection (ARTI) covers three main elements, namely infection, respiratory tract, and acuteness. Infection is the invasion of germs or microorganisms into human body in which they reproduce themselves, thereby causing disease symptoms. Respiratory tract is a set of body organs, starting from the nose to alveoli along with the adnexal organs. Meanwhile, acute infection is infection that lasts for 14 days or more. Acute respiratory tract infection (ARTI) remains to be one of the health problems faced by toddlers in Indonesia and the number one cause of death in toddlers. In addition to causing health problems, ARTI may cause death as one of the countries signing the Millennium Development Goals (MDGs) was required to be able to reduce maternal mortality rate for up to $3 / 4$ of the rate in 1990 , so that by 2015 it was expected that the rate would decrease to $102 / 100,000$ live births [1]. Another target to meet was to reduce toddler mortality rate for up to $1 / 3$ of the rate in 1990 , or $32 / 1000$ live births by 2015 .

One of the efforts made by the Ministry of Health to reduce maternal mortality rate and toddler mortality rate as well as to improve the health of mother and children is the implementation of Mother and Child Health Book. The book has been developed since 2004, and in 2007 the book was made a national policy. Unfortunately, although the Ministry of Health has implemented Mother and Child Health Book, toddler mortality rate remained high, namely $43 \%$ of the total number of toddlers in West Java [2]. West Java Department of Health has also conducted education-based training for health officers, particularly nurses, in an attempt of reducing toddler mortality and morbidity rate; however, the morbidity rate of ARTI in West Java was reported to remain high.

Another effort of reducing toddler mortality rate lies in the role of mothers of toddlers who are one of the caregivers in a family environment. Caregiver is an individual who gives both formal and informal support and assistance through various activities to people with disabilities or with long-term illness or elderly [3]. The caregiver can provide emotional or financial support and is also ready to give assistance in various tasks. In the treatment of children with ARTI, it is important to recognize various signs and symptoms of the disease and treat the children temporarily at home and immediately take the children to receive professional treatment, when the disease cannot be treated at home only. The knowledge, attitudes, and skills of mothers become the main focus in treating sick toddlers at home because mothers play the primary role in the decision making and care of children. Thus, in order to support the reduction of morbidity and mortality rates among toddlers caused by ARTI, sustainability of intensive, structured, and continuous training program is needed. The implication is 
that training should give more emphasis on the elements of knowledge, attitudes, and skills in the treatment of children with ARTI to mothers at toddlers at home.

The research then aims to find the effectiveness of the treatment training for children with ARTI in the aspects of increased knowledge, attitudes, and skills of mothers of toddlers in the working area of Puskesmas (Community Health Center) Sukajadi, Bandung.

\section{Method}

This is quasi-experimental research with pretest and posttest with control group design [4]. It involved two groups, namely the treatment group with intervention and the control group without any intervention. For each group, measurements were conducted before (pretest) and after (posttest) the intervention. In this research, the results of intervention with treatment training for children with ARTI using a module of treatment for children with ARTI at home to mothers of toddlers were compared. The control group was not given a structured training; instead, it was provided with a conventional or direct extension program. The research took place in the working area of Puskesmas Sukajadi, Bandung City, in August 2015. The population included all mothers of toddlers in the working area of the Puskesmas. The sample was taken using the equation for numerical research with paired samples, namely:

$$
n^{1}=n^{2}=n^{1}=n^{2}=\left(\frac{(Z \alpha+Z \beta)}{x^{1}-x^{2}}\right)^{2}
$$

If $z \alpha=5 \%$ (1.96), $z \beta=10 \%$ (1.28), then the previous research's standard deviation is 35 , and the difference that is considered significant $=20$, so the equation will be:

$$
n^{1}=n^{2}=n^{1}=n^{2}=\left(\frac{(1.96+0.84)}{20}\right)^{2}=24
$$

Hence, the number of sample is 24 . With an addition of $10 \%$ to anticipate drop out using the correction formula of $N=n(1-f)$ a number of 26 people were taken as sample, both for the intervention group and control group (52 in total) [5]. The sample for the intervention group of mothers of toddlers was determined by randomly selecting three out of the 10 Posyandu (integrated service pos) in Cipedes Village Administrative Unit, and the Posyandu from $\mathrm{RW}^{\star} 01$, 03, and 04 were selected. Meanwhile, the sample for control group was randomly selected from the 11 integrated service posts in Sukabungah Village Administrative Unit, and the posts from RW 01, 07, and 09 were selected. Subsequently, the stratified random sampling was done to each of the RWs in the intervention group from Cipedes and control group from Sukabungah Village Administrative Units to finally get 26 respondents as the sample for each group. Before the collection of data, the 26 mothers of toddlers of each group were given explanations about the aim of the research and signed informed consent forms. Before the 
intervention (pretest), the toddlers' mothers from both the intervention and control groups filled in a questionnaire of knowledge and attitudes for $30 \mathrm{mi}-$ nutes, while the pretest of skill was conducted by the researchers with the assistance of three cadres, in which the toddlers mothers were divided into five groups. Afterwards, each of the toddlers' mothers was given a pretest on skill for around 15 minutes. Hence, in total, each toddler's mother spent 45 minutes for the pretest of knowledge, attitudes, and skills. The questionnaire and observation sheet of the mothers' skills had been through validity and reliability tests with $r>0.762$ and $r>0.8$, for the validity and reliability, respectively.

The researchers trained the intervention group with ARTI module for mothers of toddlers for 4 - 5 hours in one day. The materials of the module that were delivered during training were: Chapter I (Introduction), consisting of background, aims, goals, objectives, and scope of the module; Chapter II (Treatment of Children with ARTI): definition, signs and symptoms, and skills on treating children with ARTI; and Chapter III (Closing). After explanations of the module, the researchers gave opportunities to the mothers of toddlers to ask if there were things that needed clarification. This was followed by the researchers demonstrating the skills on treating children with ARTI, and the mothers of toddlers were given the opportunity to re-demonstrate their skills of treating children with ARTI. The module was then brought home by the mothers of toddlers for further reading and understanding, and the mothers could practice their skills in the treatment of children with ARTI at home. Three days after the training, the researchers conducted a posttest or evaluation of training in the intervention group with the same instrument at the time of pretest. In the control group only given conventional counseling at the time of visit to Pos Yandu (Integrated Service Pos) also conducted pretest and posttest using the same instrument. For fairness, upon the completion of research, the control group was also given the module and trained on how to treat children with ARTI.

Bivariate analysis was carried out to test the mean difference of the two groups' data before and after training for each of the variables of knowledge, attitudes, and skills. The statistical tests used were the paired (dependent) and independent $t$-tests for two means with the decision rule stating that if $p$-value $<\alpha$ (0.05), then statistically there was significant effect, and if $p$-value $>\alpha(0.05)$, then then there was no significant effect.

\section{Results}

The results of the analysis of the effectiveness of treatment training for children with ARTI in improving mothers of toddlers' knowledge, attitudes, and skills are elaborated as follows:

\subsection{Univariate Analysis}

Table 1 shows that the majority of the respondents, both from intervention group (88.5\%) and control group (76.9\%), were at the category of young adults. Meanwhile, in terms of academic background, the majority respondents 
Table 1. Distribution of respondents' characteristics based on age, academic background, and occupation.

\begin{tabular}{|c|c|c|c|c|c|c|}
\hline \multirow{2}{*}{$\mathrm{NO}$} & \multirow{2}{*}{ CHARACTERISTICS } & \multicolumn{2}{|c|}{ INTERVENTION } & \multicolumn{2}{|c|}{ CONTROL } & \multirow{2}{*}{ Sig } \\
\hline & & $\mathrm{F}$ & $\%$ & $\mathrm{f}$ & $\%$ & \\
\hline \multirow{5}{*}{1} & Age & & & & & \multirow{5}{*}{0.16} \\
\hline & - 17 - 40 y.o. (young adults) & 23 & 88.5 & 20 & 76.9 & \\
\hline & - 41 - 60 y.o. (middle-aged adults) & 3 & 11.5 & 6 & 23.1 & \\
\hline & - $\quad>60$ y.o. (elder) & 0 & 0 & 0 & 0 & \\
\hline & Total & 26 & 100 & 26 & 100 & \\
\hline \multirow{5}{*}{2} & Academic Background & & & & & \multirow{5}{*}{0.04} \\
\hline & $\begin{array}{l}\text { Primary (elementary and } \\
\text { junior high schools) }\end{array}$ & 8 & 30.8 & 12 & 46.2 & \\
\hline & - Secondary (senior high schools) & 12 & 46.2 & 9 & 34.6 & \\
\hline & - Higher education & 6 & 23.1 & 4 & 19.2 & \\
\hline & Total & 26 & 100 & 26 & 100 & \\
\hline \multirow{4}{*}{3} & Occupation & & & & & \multirow{4}{*}{0.072} \\
\hline & - Employed & 15 & 57.7 & 20 & 76.9 & \\
\hline & - Unemployed & 11 & 42.3 & 6 & 23.1 & \\
\hline & Total & 26 & 100 & 26 & 100 & \\
\hline
\end{tabular}

in the intervention group (46.2\%) finished secondary education level, while the majority of the control group (46.2\%) completed primary education. Finally, most of the respondents in both the intervention (57.7\%) and control groups (76.9\%) were employed. Statistic analisys shows that demographic respondent are homogen for age and occupation.

From Table 2, it can be seen that there was an increase in the mean score of knowledge before and after intervention for the intervention group, namely from 7.73 to 9.30 . The same was also true for the control group, with an increase from 7.07 to 8.50

Table 3 indicates that there was an increase in the mean scores of attitudes before and after intervention for the intervention and control groups, namely from 53.50 to 56.26 , and from 49.53 to 52.76 , respectively.

From Table 4, it can be seen that there was an increase in the mean scores of skills before and after intervention for both the intervention and control groups, namely from 51.53 to 56.19 , and 51.84 to 54.38 , respectively.

\subsection{Bivariate Analysis}

Based on Table 5, it is clear that the difference in the mean scores of the effect of training on the knowledge of the mothers of toddler in the intervention group before and after the intervention was 1.57 , with a standard deviation of 1.17 , and $p$-value 0.000 . Meanwhile, in the control group, the difference in the mean scores of the effect of training on mothers of toddlers' knowledge before and after intervention was 1.42 , with a standard deviation of 1.20 , and $p$-value 0.000 .

Table 6 indicates that the mean difference of the effect of training on the mothers of toddlers' attitudes in the intervention group before and after intervention was 2.23 , with a standard deviation of 2.80 , and $p$-value 0.020 . On the 
Table 2. Description of mothers of toddlers' knowledge before and after training intervention.

\begin{tabular}{|c|c|c|c|c|c|c|c|c|}
\hline \multirow{3}{*}{ ELEMENT } & \multicolumn{4}{|c|}{ INTERVENTION } & \multicolumn{4}{|c|}{ CONTROL } \\
\hline & \multicolumn{2}{|c|}{ Pre } & \multicolumn{2}{|c|}{$\begin{array}{l}3^{\text {rd }} \text { days post } \\
\text { training }\end{array}$} & \multicolumn{2}{|c|}{ Pre } & \multicolumn{2}{|c|}{$\begin{array}{c}3^{\text {rd }} \text { days post } \\
\text { conventional } \\
\text { education }\end{array}$} \\
\hline & Mean & SD & Mean & SD & mean & SD & Mean & SD \\
\hline KNOWLEDGE & 7.73 & 1.53 & 9.30 & 0.83 & 7.07 & 1.52 & 8.50 & 1.02 \\
\hline
\end{tabular}

Table 3. Description of mothers of toddlers' attitudes before and after training intervention.

\begin{tabular}{|c|c|c|c|c|c|c|c|c|}
\hline \multirow{3}{*}{ ELEMENT } & \multicolumn{4}{|c|}{ INTERVENTION } & \multicolumn{4}{|c|}{ CONTROL } \\
\hline & \multicolumn{2}{|c|}{ Pre } & \multicolumn{2}{|c|}{$\begin{array}{c}3^{\text {rd }} \text { days post } \\
\text { training }\end{array}$} & \multicolumn{2}{|c|}{ Pre } & \multicolumn{2}{|c|}{$\begin{array}{c}3^{\text {rd }} \text { days post } \\
\text { conventional } \\
\text { education }\end{array}$} \\
\hline & Mean & $\mathrm{SD}$ & Mean & SD & mean & $\mathrm{SD}$ & Mean & SD \\
\hline ATTITUDE & 53.50 & 4.07 & 56.26 & 4.65 & 49.53 & 3.34 & 52.76 & 3.54 \\
\hline
\end{tabular}

Table 4. Description of mothers of toddlers' skills before and after training intervention.

\begin{tabular}{|c|c|c|c|c|c|c|c|c|}
\hline \multirow{3}{*}{ ELEMENT } & \multicolumn{4}{|c|}{ INTERVENTION } & \multicolumn{4}{|c|}{ CONTROL } \\
\hline & \multicolumn{2}{|c|}{ Pre } & \multicolumn{2}{|c|}{$\begin{array}{l}3^{\text {rd }} \text { days post } \\
\text { training }\end{array}$} & \multicolumn{2}{|c|}{ Pre } & \multicolumn{2}{|c|}{$\begin{array}{c}3^{\text {rd }} \text { days post } \\
\text { conventional } \\
\text { education }\end{array}$} \\
\hline & mean & $\mathrm{SD}$ & mean & SD & mean & $\mathrm{SD}$ & Mean & SD \\
\hline ATTITUDE & 51.53 & 4.65 & 56.19 & 4.76 & 51.84 & 4.32 & 54.38 & 5.20 \\
\hline
\end{tabular}

Table 5. The effect of the treatment training for children with ARTI at home on the knowledge of mothers of toddlers.

\begin{tabular}{ccccc}
\hline GROUP & $\mathrm{N}$ & $\begin{array}{c}\text { Difference between Pre } \\
\text { and posttest means }\end{array}$ & sd & Sig \\
\hline INTERVENTION & 26 & 1.57 & 1.17 & 0.000 \\
CONTROL & 26 & 1.42 & 1.20 & 0.000 \\
\hline
\end{tabular}

Table 6. The effect of the treatment training for children with ARTI at home on the attitudes of mothers of toddlers.

\begin{tabular}{ccccc}
\hline GROUP & $\mathrm{N}$ & $\begin{array}{c}\text { Difference between pre } \\
\text { posttest means }\end{array}$ & sd & $p$-value \\
\hline INTERVENTION & 26 & 3.23 & 2.80 & 0.020 \\
CONTROL & 26 & 2.96 & 3.26 & 0.050 \\
\hline
\end{tabular}

other hand, the mean difference of the effect of training on the attitudes of the mothers of toddlers before and after intervention was 2.96, with a standard deviation of 3.26 and $p$-value 0.050 .

Table 7 illustrates that the mean difference of the effect of the training on the 
skills of the mothers of toddlers before and after intervention for the intervention group was 4.88 , with a standard deviation of 3.06 and $p$-value 0.030 . Meanwhile, in the control group, the mean difference of the effect of the training on the mothers of toddlers' skills before and after intervention was 2.53, with a standard deviation of 3.11 and $p$-value 0.010 .

From Table 8, it can be observed that the mean scores of the intervention group and control group were 0.22 and 0.28 , respectively, and $t=1.63$ with $p$-value 0.030 . This result proves that the training intervention had significant effect and was effective in improving the knowledge of the mothers of toddlers. This inference is made after comparing the mean scores between the intervention group and control group.

Table 9 indicates that the mean scores of the intervention group and control group were 0.77 and 0.74 , respectively, and $t=1.28$ with $p$-value 0.046 . This result proves that the training intervention had significant effect on and was effective in improving the attitudes of the mothers of toddlers. This inference is drawn after comparing the mean scores of attitudes for the intervention group and control group.

Table 10 demonstrates that the mean scores of the intervention group and control group were 0.16 and 0.19 , respectively with $t=1.15$ and $p$-value 0.042 .

Table 7. The effect of the treatment training for children with ARTI at home on the skills of mothers of toddlers.

\begin{tabular}{ccccc}
\hline GROUP & $\mathrm{N}$ & $\begin{array}{c}\text { Difference between pre } \\
\text { posttest means }\end{array}$ & sd & $p$-value \\
\hline INTERVENTION & 26 & 4.88 & 3.06 & 0.030 \\
CONTROL & 26 & 2.53 & 3.11 & 0.010 \\
\hline
\end{tabular}

Table 8. The effectiveness of the treatment training for children with ARTI at home in improving the knowledge of mothers of toddlers.

\begin{tabular}{ccccc}
\hline GROUP & $\mathrm{N}$ & mean & $t$ & $p$-value \\
\hline INTERVENTION & 26 & 0.22 & 1.63 & 0.030 \\
CONTROL & 26 & 0.28 & & \\
\hline
\end{tabular}

Table 9. The effectiveness of the treatment training for children with ARTI at home on the attitudes of mothers of toddlers.

\begin{tabular}{ccccc}
\hline GROUP & $\mathrm{N}$ & mean & $t$ & $p$-value \\
\hline INTERVENTION & 26 & 0.77 & 1.28 & 0.046 \\
CONTROL & 26 & 0.74 & & \\
\hline
\end{tabular}

Table 10. The effectiveness of the treatment training for children with ARTI at home on the skills of mothers of toddlers.

\begin{tabular}{ccccc}
\hline GROUP & $\mathrm{N}$ & mean & $t$ & $p$-value \\
\hline INTERVENTION & 26 & 0.16 & \multirow{2}{*}{1.15} & 0.042 \\
CONTROL & 26 & 0.19 & & \\
\hline
\end{tabular}


The scores proved that the training intervention had significant effect and was effective in improving the skills of the mothers of toddlers. This inference is drawn after comparing the mean scores of skills for the intervention group and control group.

\section{Discussion}

The research results presented in Table 1 support the claim of the effectiveness of treatment training for children with ARTI to mothers of toddlers. Meanwhile, Tables 2-4 show that the training intervention of the treatment of children with ARTI using the medium of training module significantly affected the improvement in the knowledge, attitudes, and skills of the mothers of toddlers. Meanwhile, the research results in Tables 5-7 demonstrate that there was a difference in the mean scores of knowledge of the intervention group between pre and posttests with $p$-value $=0.000$. There was also a difference in the mean scores of attitudes with $p$-value $=0.020$. Similarly, a difference in the mean scores of skills was also obtained, with $p$-value $=0.030$. The mean differences indicate that the training using learning module had effect on the knowledge, attitudes, and skills of the mothers of toddlers. The findings show that almost half of the mothers $(48.6 \%)$ as respondents in her research had very limited knowledge about ARTI disease which might be due to their level of education, in which almost half of them were graduates of primary school (45.7\%) [6]. Therefore, teaching and learning through training with the medium of a module is really necessary in order to increase knowledge. Learning theory as a theory that offers explicit guidelines on how to help people learn and develop better [7]. The types of learning and development include the cognitive, emotional, social, physical, and spiritual aspects. It means that experience-based learning has several characteristics, namely: 1) design-oriented, which means it is focused on the attempt of meeting learning goals; 2 ) identifying learning methods (ways to support and facilitate learning) and the situations during which the method can/cannot be used; and 3) the learning method can be elaborated into lesson plan.

Knowledge can be gained from the medium of learning module because basically learning using a module provides students with an opportunity to learn autonomously [8]. Attitudes are always linked to the behaviors that are still within limits and considered normal, which are responses or reactions to a certain stimulus, although attitude is essentially only the predisposition or tendency to behave in a certain way, so that it cannot be said as an action or activity [9]. In this regard, a nurse as an educator, a caregiver, a facilitator, and an advocator plays an important role in an attempt of empowering and enabling mothers/families of toddlers [10]. Attitude is affected by the information given by others who have acquired or formed a certain attitude towards a certain object based on their direct experience. An individual who obtains accurate information by him/herself will gain a direct experience of the object. Changes in attitude can be in the form of an addition to, a shift, or modification of one or more components, which means that one or more components of attitude may 
change, but the other components remain unchanged. The factors of experience and maturity are highly influential in an individual's attitude changes.

Tables 8-10 indicate that the mean scores of knowledge for the intervention group and control group were 0.22 and 0.28 , respectively, with $t=1.63$ and $p$-value 0.030 . The mean scores for attitude of the intervention group and control group were 0.77 and 0.74 , with $t=1.28$ and $p$-value 0.046 . Meanwhile, the mean scores of skills for the intervention group and control group were 0.16 and 0.19 , respectively, with $t=1.15$ and $p$-value 0.042 . The results proved that the treatment training for children with ARTI at home using the medium of learning module was effective. Training using a module as guidelines has been implemented in various efforts of improving knowledge [11]. Module is one of good and effective learning media to assist students in planned and continuous teaching and learning processes. Module is also an effective individual learning system with the main goal of increasing learning effectiveness and efficiency. A module can be used at home, so that the module can be studied anywhere. In addition, the duration of learning using a module can last from several minutes to hours and can be done by oneself or combined with other methods. The treatment training for children with ARTI using learning module was effective, for the module can be studied and applied at home [12].

The sub-variable of skills showed the greatest increase or improvement compared to the two other subvariables. The results indicated that the treatment training for children with ARTI using learning module at home had significant effect on changes in the skills of the mothers of toddlers, as proven by $p$-value $0.03<0.05$, which means the training had effect on the skills of the mothers of toddler, and the increase was statistically significant, as can also be seen by the scores displayed in Table 7. The effectiveness of the training is also proven by the results presented in Table 10. Bloom's theory explain that there are three domains of human behavior [13]. The classification is made for the interest of education goals, namely knowledge, attitude, and its prediction for behavior. The cognitive component contains perception, belief, and stereotype possessed by an individual regarding something and behavior/skill has one or more measurable dimensions, namely frequency, duration, and intensity [14]. Behavior/ skill can be observed, explained, and recorded by others or the people involved in the behavior [15]. An individual's behavior in performing a certain skill is also situational, meaning that each individual will behave differently in different situations.

Based on the above explanations, it can be concluded that the training of mothers of toddlers using a module of treatment for children with ARTI at home was effective.

\section{Limitations of the Study}

The limitations in this study are difficulties in controlling the respondent's variables. 1) Academic background are heterogent between intervention group and control group. 2) There are difficulity to control biased during training such as: 
concentration, motivation and barriers of the environment during the training/intervention.

\section{Conclusion}

The results of this research show more significant increases in the mean scores of knowledge, attitudes, and skills of the mothers of toddlers who were given intervention than the scores of those who were not given any training, which means that the treatment training for children with ARTI at home was proven to be effective and had significant effect on the increased knowledge, attitudes, and skills of the mothers of toddlers.

\section{Suggestions}

Based on the research results, the following recommendations are formulated: 1) The results of this research can be made a topic of study for developing a model or standardized training guidelines; 2) The results can be made the basis for community service programs to improve people's health in an attempt of reducing toddler morbidity and mortality rates caused by ARTI.

\section{References}

[1] National Institute of Health Research and Development (2008) Correlation between Environmental and Socio-Economic Factors (ARTI and Diarrhea Complaints). Retrieved from http://digilib.litbang.depkes.go.id.php/

[2] Department of Health (2012) West Java's Health Profile. Bandung.

[3] World Health Organization (2007) Prevention and Control of Acute Respiratory Tract Infection in Health Service Facilities. Retrieved from http://www.who.int/csr/resources/publications/AMpandemicbahasa.pdf

[4] Grove, S.K., Burn, N. and Gray, J.R. (2013) The Practice of Nursing Research: Appraisal, Synthesis, and Generation of Evidence. 7th Edition, Elsevier Sounders, St. Louis Missouri.

[5] Ariawan, I. (2008) Sample Size and Methods in Health Research. Faculty of Health Community University of Indonesian, Jakarta.

[6] Silviana, I. (2014) Correlation between Mothers' Knowledge about ARTI and ARTI Prevention Behaviors for Toddlers at PHPT Muara Angke, Jakarta in 2014. Faculty of Health University of Esa Unggul Jakarta. The Forum of Science, 11, 402-411.

[7] Azwar, S. (2005) Human Attitudes, Theory, and Measurements. PT Pustaka Pelajar, Jogyakarta.

[8] Sungkono (2013) Developing and Using Module as Teaching Materials in Instructional Processes. Retrieved from https://andridm72.wordpress.com/ilmu/

[9] Sunaryo (2004) Psychology for Nursing. EGC, Jakarta.

[10] Hall, C.S. and Lindzey, G. (2012) Theories of Personalities. Kanisius, Yogyakarta.

[11] Shankar, P.R., Singh, K.K. and Priyani, R.M. (2012) Knowledge, Attitude and Skills before and after a Module on Pharmaceutical Promotion in a Nepalese Medical School. BMC Research Notes. Retrieved from http://www.biomedcentral.com/1756-0500/5/8

[12] Oroh, S., Umboh, J.M.L. and Kapantow G.H. (2014) Correlation between Mothers' Knowledge and Smoking Habit of Family Members and the Occurrence of Acute 
Respiratory Tract Infection among 1 - 4 Year Old Children at Puskesmas Tumpaan, South Minahasa Regency. Faculty of Health Community University of Sam Ratulangi. The Journal of Community Health STIKES Wirahusada in Environmental Science, 7, 161-166.

[13] Wijayanti, R. and Purwandari, H. (2006) The Impacts of Modules on Families' Increased Knowledge and Skills in Stimulating Infants' Growth and Development. The Soedirman Journal of Nursing, 1, 83-90.

[14] Hayati, S. (2014) Description of the Factors Causing ARTI among Toddlers in Community Health Centre Pasirkaliki, Bandung City. Faculty of Nursing University of BSI. The Journal of Nursing Science, 11, 62-67.

[15] Prabu (2009) Acute Respiratory Tract Infection. Retrieved from http://prabu.wordpress.com/2009/01/04/infeksi-saluran-pernafasan-akut-ispa.

Submit or recommend next manuscript to SCIRP and we will provide best service for you:

Accepting pre-submission inquiries through Email, Facebook, LinkedIn, Twitter, etc. A wide selection of journals (inclusive of 9 subjects, more than 200 journals)

Providing 24-hour high-quality service

User-friendly online submission system

Fair and swift peer-review system

Efficient typesetting and proofreading procedure

Display of the result of downloads and visits, as well as the number of cited articles Maximum dissemination of your research work

Submit your manuscript at: http://papersubmission.scirp.org/

Or contact ojn@scirp.org 